\title{
Organization and financing of home nursing in the European Union
}

\author{
Ada Kerkstra PhD \\ Co-ordinator, Nursing and Canng Research \\ and Jack B F Hutten MSc \\ Research Fellow, Netherlands Institute of Primary Health Care (NIVEL), Utrecht, \\ The Netherlands
}

KERKSTRA A \& HUTTEN J B F (1996) Journal of Advanced Nursing 24, 1023-1032

Organization and financing of home nursing in the European Union

The alm of this study was to provide an overview of the organization and

financing of home nursing in the 15 member states in the European Union Home nursing was defined as the nursing care provided at the patients' home by professional home nursing organizations Data were gathered by means of three complementary research methods desk research, postal questionnaure among identified experts and face-to-face interviews with experts The results showed that there are large differences between the countries in the way home nursing care is financed There seems to be a relation between the way of funding and the organizational structure In member states where the organizations receive a fixed budget, based on the number of inhabitants or the demography of the catchment area, home nursing is mainly provided by one type of organization and is freely accessible for the patients In this situation there is little competition among the organizations, and the catchment areas of the regional organizations do not tend to overlap On the other hand, in countries where organizatıons are reimbursed according to a fee-for-service principle and a referral of a doctor is required, home nursing is provided by different types of organizations and also by independent nurses It seems that fee-for-service reimbursement stımulates competition between providers and a marketoriented home care In addition, a fee-for-service method of funding also has the consequence that mainly technical nursing procedures and some basic care are reimbursed, this leaves little room for nurses to perform preventive and psychosocial activities or to provide more integrated care

\section{INTRODUCTION}

The Treaty of Maastricht in 1992 was an important step towards a greater integration of the separate countries within the European Union The union, which started as a purely economic organization onginally called the European Economic Community (EEC), now also finds

Correspondence Ada Kerkstra, Netherlands Instutute of Primary Health Care (NIVEL), PO Box 1568, 3500 BN Utrecht The Netherlands itself in a process of mutual co-operation and integration of policies in other areas such as education, culture, social security and health care Consequently, information about the present situation in home nursing is required to improve communication and co-operation among home nursing organizations as well as among policy makers at a European level In addition, the increasing integration of the member states is also reflected in the extended opportunities for nurses to work in other countries (free movement of people within Europe) Although there are 
European Union guidelines concerning the education and training of nurses, it is also important for nurses who want to work in home care in another country to know about the organizational context of home nursing in the other member states of the European Union

\section{Elderly people}

Nearly all countries of the European Union are being confronted with a steady increase of the percentage of the elderly in their populations The proportion of people over 80 years of age, in particular, is increasing rapidly (Statıstical Yearbook of Norway 1990, Organization for Economic Cooperation \& Development 1990) This leads to a rise in the demand for professional home care which is enforced by the fact that the role of informal carers, such as family members and friends, is decreasing in most of the countries Smaller families, a growth in women's employment and an increasing number of elderly single people are the main causes of this development (Walker 1991)

A second common problem is the development of health care expenditure Owing to an increase of the costs of health care, governmental policies are increasingly focused on home care instead of institutional care (both residential care for the elderly and hospital care for the sick) The anm is to enable elderly people to stay in their own homes for as long as possible and to limit their length of stay in hospitals (Walker 1991, Ny)kamp et al 1991, Abel-Smith \& Mossialos 1994)

Finally, besides a quantitative growth in the demand for home care, there are also important changes in the content of the care provided Because of epidemiological developments, the policy to substitute home care for hospital care and the increase in opportunities to provide technically advanced medical treatments at home, the nature and complexity of home nursing is changing

In this study home nursing is defined as the nursing care provided at the patients' home by professional home nursing organizations Home nursing services include rehabilıtative, supportive, health promotive or disease preventive, and technical nursing care The emphasis is mainly on the nursing of sick people at home Other possible community nursing activities are not included, e g preventive mother and child health care, psychiatric care, midwifery, school health nursing and occupational nursing This means that, for instance, in the United Kingdom only district nursing is considered For an overview on two specific subjects in home nursing, 1 e experiments on 'hospital care at home' and rehabilitation technology in home care in Europe we refer to two recent other studies (de Witte et al 1994, Raffy-Pihan 1994)

\section{THE STUDY}

The aim of this paper is to provide an overvew of the organization and financing of home nursing in the $\mathbf{1 5}$ member states of the European Union Austria, Belgium, Denmark, Finland, France, Germany, Greece, Ireland, Italy, Luxembourg, the Netherlands, Portugal, Spain, Sweden and the United Kingdom Firstly, regarding the financing, an overvew will be given of the funding of home nursing organizations and whether or not co-payment of the patient is required Secondly, an overview is presented of the organization of home nursing, $1 \mathrm{e}$ of the organizational structure of home nursing, manpower and the accessibility of the services Finally, the relations between home nursing and home help services in the provision of home care are described The study is building on an earlier study into community nursing in five member states by one of the authors (Verhel] \& Kerkstra 1992) and on the research of Jamieson (1991) into home help services in seven countries of the European Union

\section{METHODS}

Following the research of Verhey \& Kerkstra (1992), three complementary research methods were used

Desk research Research commenced with an investigation of the literature that was avalable in the files of the Netherlands Institute of Primary Health Care (NIVEL), the University of Utrecht and the international database Medlıne This largely provided a general description of the health care system in each country Broadly speaking, there were only a limited number of references to our research topic

Postal questionnaire to experts Experts on home nursing were contacted in all countries Preference was given to people engaged in research into community nursing or involved in home care policy, both at professional or governmental level, because it was important that they were able to provide a national overview The experts were identıfied by means of

- personal contacts of NIVEL, e g from earher research in this field and partıcipation in international conferences about this subject,

- contributions to the literature on home nursing, e g partıcipants in the studies of Nijkamp et al (1991) and Verhel] \& Kerkstra (1992),

- members of the European Association of Organizations for Home Care and Help at Home

Two factors determined the number of experts needed in a country the amount of already avallable information about home nursing in a certain country and whether or not large regional differences exist in the organization of home nursing within a country When it concerned only updating of already avalable information, one or two 
experts were sufficient This was the case for instance in Belgium, Finland, Germany, Ireland, the Netherlands and the United Kingdom In the other countries at least five (e g in Greece, Italy, Luxembourg) or even 11 (in Spain) identified experts participated in the study

A comprehensive questionnaire, in English, was sent to all experts The questionnaire was in two parts Part one contained questions on the organization of home nursing Topics discussed were the organizational structure, the type of nurse working in home care, the patients or clients, and the way services were provided Part two contained questions on the financial aspects, $\mathrm{e} g$ the funding of the home nursing organizations, the insurance system and (co-)payments by patients

To allow comparison of the information from the 15 countries, one reference date was chosen - the end of December 1993 - unless important changes had taken place in 1994 When quantitative information was required, concrete and the most recent figures based on official statistics or research results were preferred However, if such published information was not avalable in the country, participants were asked to make their own estımate for 1993 The experts were also requested to send, if avalable, relevant publications or documents about those topics

Interviewing experts In addition, experts in Austria, Denmark, Finland, France, Germany, Italy, Luxembourg, Sweden and the United Kingdom were visited personally by one of the researchers to collect additional information, e g about recent developments

After all information had been collected, a draft report on home nursing in each country was written and returned to the national experts for correction and additions For detailed information per country, we refer to the research report (Hutten \& Kerkstra 1995)

\section{RESULTS}

It was found that in all 15 countries of the European Union home nursing is part of the health care system Only in Sweden, since 1992 as part of the reform of the health care system, will home nursing no longer belong to primary health care, but to the social services In some regions in Italy home nursing care is also provided within social services

Although home nursing belongs to health care in the European Union, there are large differences between the member states in the history of home nursing In Belgium, Denmark, Finland, Ireland, the Netherlands and the United Kingdom home nursing already has a long tradition and was developed many years ago, whereas in some other countries such as Austria, Greece, Italy, Luxembourg, Portugal and Spain home nursing only developed in the last 15 years or is stull being developed In some countries home nursing has a religious background, for example, in (formerly West) Germany, this can still be seen in the system of umbrella organizations each with its own religious affiliation However, in a country like Denmark home nursing became the responsibility of the local government at a relatively early stage Finally. France, Spain, Italy and especially Greece do not yet have home nursing in every region of the country

\section{The financing of home nursing}

\section{Funding of home nursing organizations}

In all countries studied, home nursing organizations were usually non-profit In some countries, however, costcontainment measures include the introduction of competitive elements in the health care system This may mean the advent of a for-profit sector in home nursing too

Two funding models for home nursing organizations can be distingurshed (Figure 1)

In the first model, home nursing is mainly financed from general taxation The home nursing organizations recelve a fixed budget from the central government or local authorities The budget generally depends on the number of inhabitants or the number of elderly people in the catchment area In this model, patients have direct access to the home nursing organization which means that no referral of a doctor is needed This is the predominant model in Denmark, Ireland, Italy, Portugal, Span, Sweden and the United Kingdom

However, the funding system in the United Kingdom is undergoing a significant change In the old system model 1 was applied, $1 \mathrm{e}$ the district health authorities received a fixed budget based on the number of inhabitants and the demography of the population In the new system, the funding of the new community trusts is based on the services that they deliver to patients This means a shift from

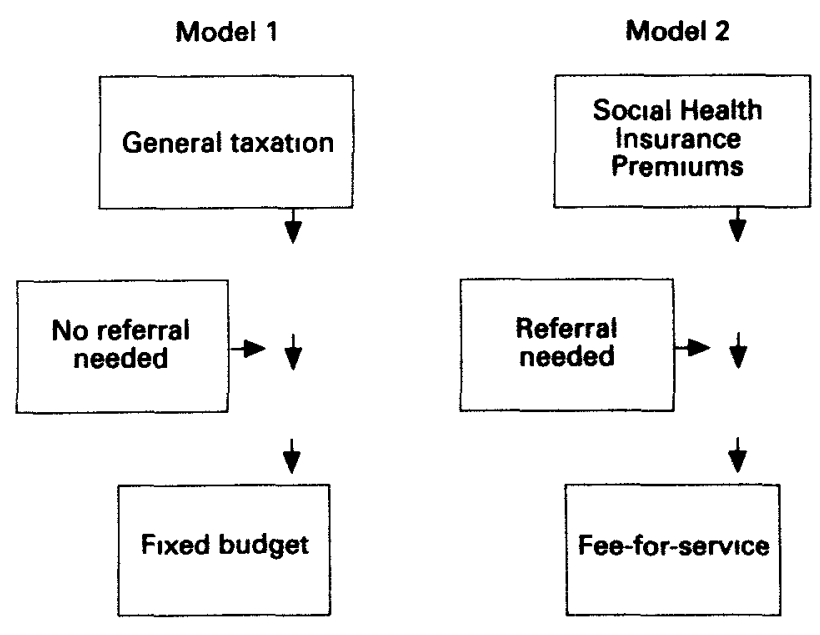

Figure 1 Two models of funding home nursing organizations in the European Union 
fixed budget funding to a fee-for-service reimbursement At present both systems co-exist

In the second model, home nursing is largely financed through a social health insurance scheme In these countries the premuums for these compulsory schemes are pad for by employees and/or employers In this model home nursing organizations are reimbursed on a fee-for-service basis To receive the reimbursement, a medical referral is required This is the predominant model in Austria, Belgium, France, Germany and Luxembourg

There are various types of reimbursement on a fee-forservice basis In the most simple type, reimbursement takes place on the basis of a list of nursing activities (nomenclature) and states the price of these activities This price can be reimbursed to the home nursing organization or to the patient This method is part of the reimbursement system in Austra, Belgium, Luxembourg and France In these countries mainly technical nursing procedures are reimbursed and hardly any preventive or psychosocial activities Especially in Austria and Luxembourg only technical nursing procedures prescribed by a doctor are reimbursed In these countries, more basic nursing care like bathing and help with getting out of bed is not reimbursed and has to be pand by the patients themselves However, in Luxembourg, people living at home who need care recelve as part compensation a monthly government allocation and in Austria, since 1993, everyone who is in need for home care for more than 6 months can apply for an attendance allowance (Pflegegeld) by the municipality

Reimbursement can also take place based on the number of home visits Here a distinction is made between various types of home visits according to the type of care that is delivered during these visits This is the case in Germany, where a distinction is made between Grundpflege, which involves mainly personal hygienic care, and Behandlungspflege, concerning technical nursing procedures as a support for medical treatment However, in 1995 in Germany the funding system changed Patients are now categonzed into three levels of need for nursing The home nursing organization recelves a reimbursement per patient per month according to the level of care dependency of the patient There is a maximum allowance for each category Furthermore, it is also possible to provide a budget to the patient himself, allowing him to buy his own home care

A third type of fee-for-service reimbursement is based on the number of days of care This is part of the system in Belgium, as far as heavily or moderately dependent patients are concerned The amount rembursed varies with the level of care dependency of the patient

In France, a special form of the fixed budget method exusts in addition to the fee-for-service system Here the organization is authorized by the health insurance funds to care for a fixed number of patients under two schemes 'hospitalization at home', under this scheme most patients are discharged from hospitals, and 'elderly care at home' Patient's reimbursement is about three times as high for 'hospitalization at home'

Finally, in Finland, Greece and the Netherlands a mixture of the two models is used Home nursing in Finland is funded from general taxation and the health centres which provide nursing care receive a yearly fixed budget from the municipalities, however patients have to be referred by a general practitioner In Greece no referral of a doctor is needed, but only the home nursing organizations of the national health services and the Hellenic Red Cross recelve a fixed budget, private organizations are reimbursed on a fee-for-service basis In the Netherlands, home nursing is financed by a compulsory social health insurance scheme, but the home nursing organizations recerve a fixed budget based on the number of personnel, and no referral from a doctor is needed to recelve home nursing care In 1995, however, the funding system changed, and the budget is now based on the number of hours of care provided

\section{Co-payments by the chents}

In the majority of the member states there is no co-payment for home nursing, that is home nursing services are usually free of charge or are reimbursed by the patients' health insurance Table 1 shows that in Denmark, Germany, Ireland, Portugal, Spain and the United Kingdom patients do not have to pay for home nursing In Belgium and the Netherlands only small membership fees have to be pard to the home nursing organization The membership fee in the Netherlands is about NLG 50 (£20) a year per famly and in Belgium the membership fee of the White-Yellow Cross varies between 500 and 1000 BFR (£11-22) per family per year Furthermore, in Belgium and France co-payment depends on the type of insurance of the patient However, in these countries most people are additionally insured and therefore do not have to pay So, in these nine countries, home nursing is (almost) free of charge for the patients

As mentioned before, in Austria and Luxembourg co-payment is required for general basic nursing care, but not for technical nursing care prescribed by a doctor In Italy, whether or not co-payment is required depends on the type of organization Home nursing provided by the local health units of the national health services is free of charges, whereas for home nursing provided by the social services of the communities and by private organizations, co-payment is required The level of co-payment is income-related and varies between the communities because the amount is determined by the local authorities In some communities no co-payment is required

Finland, Greece and Sweden are the only countmes where all patients have to pay fees themselves For occasional nursing care in Finland, a fee of 30 FIM ( $£ 4-5)$ per visit by a nurse is charged Concerning a longer epısode 
Table 1 Co-payment for home nursing in the European Union

\begin{tabular}{lll} 
Non co-payment required & Co-payment sometımes required & Co-payment requred \\
\hline Denmark & Austria, dependent on type of care & Belgium (membership fee) \\
Germany & Belgium, dependent on insurance & Finland \\
Ireland & France, dependent on insurance & Greece \\
Portugal & Italy, dependent of type of organization & Netherlands (membership foe) \\
Spain & Luxembourg, dependent on type of care & Sweden \\
United Kingdom & &
\end{tabular}

of care, all patients have to pay a percentage of the costs themselves

The level of co-payment depends on monthly income and the size of the famly and varied, in 1994, from 11 to $35 \%$ In Greece, for all nursing services at home a co-payment of about $20 \%$ of the costs is required With regard to co-payment in Sweden a distinction must be made between home nursing care provided by county councils (health care) and by the municipalities (social services) In the first situation, patient's fees for home nursing care are a part of a general co-payment scheme for primary health care (with a maximum amount of 1600 SEK (£150) a year in 1994) However, this also includes other kinds of primary health care such as dental care and pharmaceutucals The exact amount charged per home nursing visit can differ between the regions It is estimated that the average is about 50 SEK $(£ 4-5)$ The fees are not income-related The municipalities providing home care can operate different co-payment schemes for home nursing activities Sometimes they are included in the total home care fees (including also home help) and it is also possible that the municipalities include the fees in the health care payment system which is mentioned above

\section{The organization of home nursing}

\section{Organizational structure of home nursing}

Related to the differences in financing of home nursing, there are also differences in the organizational structure of home nursing between the member states, that is the countries differ with respect to the number of different organizations that provide home nursing (Table 2)

In seven countries, Denmark, Finland, Ireland, the Netherlands, Portugal, Sweden and the United Kungdom, home nursing is provided by mainly one type of organization As mentioned before, in all of these countries the community nursing organizations recerve a fixed budget, although the Netherlands and the United Kingdom are in a transition period towards a fee-for-services funding In Denmark home nursing is provided by the municipalities (the local communities) by the same department as home help services At a national level the association of commumities negotiates with the nurses' association about
Table 2 Organizational structure of home nursing in the European Union

\begin{tabular}{lll}
\hline $\begin{array}{l}\text { Mainly one type } \\
\text { of organization }\end{array}$ & $\begin{array}{l}\text { Mainly two types } \\
\text { of organization }\end{array}$ & $\begin{array}{l}\text { Three or more types } \\
\text { of organization }\end{array}$ \\
\hline $\begin{array}{l}\text { Denmark } \\
\text { Finland }\end{array}$ & Belgium & $\begin{array}{l}\text { Austria } \\
\text { Ireland } \\
\text { The Netherlands }\end{array}$ \\
$\begin{array}{l}\text { France } \\
\text { Sortugal }\end{array}$ & Germany & $\begin{array}{l}\text { Italy } \\
\text { Luxembourg }\end{array}$ \\
United Kingdom & & Spain \\
\hline
\end{tabular}

general guidelines for the relationshıp between the number of head nurses, nurses and assistant nurses at community level In Finland health care is also mainly the respons1bility of the muncipalities The actual home care is provided from health centres The local authonties appoint a health board which puts a health manager in charge of the health centre In Ireland home nursing is provided by public health nurses employed by statutory health boards, which operate in eight geographical areas In the Netherlands home nurses are employed by the so-called Regional Cross Associations or Home Care Organizations

The Cross Associations are members of the umbrella organization The National Association for Home Care which determines policy on the national level In Portugal the national health service covers the whole country with a network of health centres Home nursing is provided by nurses employed by the health centres In Sweden the county councils were responsible for home nursing The care was mostly delivered from primary health care centres However, the Care of the Elderly reform in 1992 moved the responsibility for care of elderly people, including home nursing, towards the municipalities At the end of 1994 , in about $50 \%$ of the counties home nursing had already been delegated to the municipalities, and this reform process is stull going on As a consequence of this reform, home nursung becomes a part of social services and will belong to the same organization as the home help services Finally, in the United Kingdom home nursing is also part of the national health service and is provided by 
the community unit of the district health authonties or since the reform of the national health services in 1990 by the community trusts

In three other countries, Belgium, France and Germany, home nursing is provided by mainly two types of organizations As we have seen before the home nursing organizations in these countries are rembursed on a fee-forservices basis In Belgium the largest organization is the White-Yellow Cross which covers the whole country and performs about $50 \%$ of all home nursing activities The much smaller organization is Solidarity for the Family, which provides both home nursing and home help services Besides these two organizations an increasing number of independent nurses are working in private practices It is estimated that about $40 \%$ of the market is covered by independent nurses In France the majority of home nursing activities is provided by private non-profit organizations About one third is delivered by the municlpalities In addition, there is a large number of independent nurses In many cases independent nurses are hired by home nursing organizations In Germany home nursing is provided by the so-called Gemeindekrankenpflegestationen and increasingly by the so-called Sozıalstationen, which also provide home help services The total of all these non-profit organizations is called the Frese Wohlfartspflege Though the market of home nursing is dominated by non-profit organızations, in recent years a growing number of nurses have decided to work freelance or have developed for-profit nursing organizations, especially in the urban areas For instance, in Hamburg, $60 \%$ of home nursing is delivered by for-profit providers

Finally, in five countries, Austria, Greece, Italy, Luxembourg and Spain, home nursing is provided by three or more different organizations Those are also the countries in which home nursing was only developed recently or still has to be developed in some parts of the country Nowadays professional home nursing exists nearly everywhere in Austna In most provinces of Austria four or more types of organization provide home nursing Some of them also provide home help services Home nursing care is provided mainly by independent charity associations but also by organizations which are set up by political parties and by self-organized groups in private business There are, however, large differences between the provinces in the way home nursing is organized In many parts of Greece home nursing services still do not exist In some regions home nursing is provided through the national health services by nurses from the hospitals, in the big citses home nursing is mostly delivered by for-profit private organizations or by the non-profit Hellenic Red Cross A main problem in the description of home nursing in Italy is the lack of a general terminology about what kund of services should be provided For example, there is still a discussion whether home care for the chronically ill is a matter of the health care system or of the social services

Officially, home nursing services are part of the national health service, but they do not yet extend to the entre country However, in many places home nursing is still organized by the social services of the municipalities and there are an increasing number of private organizations providing home nursing In the smallest member state of the European Unıon, Luxembourg, the two largest organizations for home nursing are Hellef Doheem and the Croix-Rouge In addition there are four smaller organ1zations, two of them are non-profit organizations that also provide home help services Together these six organizations cover the whole country Finally, home nursing is provided within the Spanish primary health care system, which now covers $\approx 65 \%$ of the total Spanish population Between the communities large differences exist in the types of home nursing provided Home nursing has still to be developed in the more rural parts of the country

\section{Manpower}

In 11 countries there are at least two levels of expertise in home nursing In general, the length of the basic education of the first expert level nurses varies between 3 and 4 years The length of education of the second expert level nurses varies between 1 and 3 years Thus, there appears to be a lot of variation A second level home nurse from the Netherlands, for example, has had three times as much training as a second level home nurse in France In the remaining four countries, Italy, Luxembourg, Portugal and Spain, only registered or first level nurses are employed in home care Maybe, this is due to the fact that home nursing in these countries only started recently Another reason is that, for example, in Portugal, the tasks of home nurses are strictly limited to technical nursing procedures, health education, psychosocial care and support of informal carers Personal hygiene care, such as bathing, is not a nurse's task

In all countries, the lower level nurses are always more involved with personal hygiene care and uncomplicated technical nursing than those with higher level qualifications The most highly differentiated system is used in United Kungdom the clinical gradıng structure for nursing staff, whuch was introduced in 1988, has nine grades Each grade has its own task profile and required qualification and experience In Belgium, on the contrary, there is no task differentiation between first and second expert level nurses in home care, both types of nurses have the same legal competence

Unfortunately it is not possible to make a cross-national comparison on nurse population ratios, because only organization-specific information about the number of nurses is avaulable for most countries, for other countries this information is only avalable for particular regions 
Despite the himitations of the data, it was stall considered useful to look at the way in which levels of expertise relate to each other

Much is dependent on the definition of the first and lower levels in each country and the figures should be considered with much caution, however it is legitimate to state that Greece, Belgrum and France have a high number of lower level nurses compared to the other countries Special attention must also be given to the fact that the figures concerning Greece are based on estumates and that there is a severe shortage of qualıfied nurses in Greece In Sweden the home care assistants includes nursing assistants and qualified home helps No differentiation is made between these two types of professionals because their actual tasks look more and more alke However, one has to keep in mind that approxamately $80 \%$ of their working tume is spent on home help activities instead of home nursing care Comparison with the figures of the study of Verhel] \& Kerkstra (1992) showed that, during the last few years, the relative number of lower level nurses in the Netherlands and the United Kingdom has increased, while in Belgium the number of second level nurses has decreased in relative terms

\section{Accessiblity of home nursing}

In all countries it is largely elderly people who receive nursing care at home They form the largest client population for home nurses When patients need nursing care at home, in almost all cases they have no choice as to which home nursing organization they can approach, either because there is only one home nursing organization in their region, or because, like in Austria, the health insurance company of the patient has a contract with a particular home nursing organization Belgium is the only exception recently the opportunity to choose between home nursing care delivered by formal organizations like the White-Yellow Cross and home care by independent nurses has increased considerably

As mentioned before, in some countries a medical referral is requred for nursing care at home, while in other countries patients can contact the home nursing organizatons themselves In Denmark, Greece, Ireland, Italy, the Netherlands, Portugal, Spain, Sweden and the United Kingdom no medical referral is needed In Austria and Luxembourg a formal referral is only needed for (complicated) technical nursing, necessary for reimbursement, and not for other types of nursing care In France and Germany a physician's prescription is needed for all types of care eligible for reimbursement In Belgium this is true with the exception of hygienic care

As a consequence, countries also differ in respect of who makes the assessment of the patients' need (Table 3)

In Austria, Denmark, Ireland and United Kingdom the assessment is made by the first level nurse who is also going to provide the care or have it provided by a lower
Table 3 Professionals making the assessment of patients' need for home nursing in the European Union

\begin{tabular}{lll}
\hline Qualified home nurse & $\begin{array}{l}\text { Qualified home nurse } \\
\text { and/or physician }\end{array}$ & Physician \\
\hline Austria & Belgium & France \\
Denmark & Finland & Germany \\
Ireland & Greece & \\
The Netherlands (partly) & Italy & \\
Sweden (partly) & Luxembourg & \\
United Kingdom & Portugal & \\
& Spain & \\
\hline
\end{tabular}

level nurse In the Netherlands, within the process of integration with the home help services, most home care organizations plan to combine the assessment of patient need for home help and nursing care There is a debate about who pays the assessment visits a first level nurse who also provides care, a manager of the home help services or a special assessment team The fact is that the health insurance companies demand more standardized and objective methods of assessment and support solutions, including special assessment teams, more or less outside the care-giving organization At this moment, therefore, who pays the assessment visits depends on the organization Within the Swedish home nursing system, two different methods exist When the nursing care is the responsibility of the county councils, the assessment is made by a registered nurse working in a primary health care centre, but when the care is provided by the municipalities, the assessment is the responsibility of the home help administrator of the social service department The decision is made within the frame work of the Social Services Act The home help administrator mostly assesses the total need for home care both home nursing and home help needs

In Finland, Greece, Italy, Luxembourg, Portugal and Spain the assessment is frequently carred out by a nurse together with or (sometimes) by a physician, depending solely on the patient's need In Belgium, patients have a prescription from their general practitioner, which is necessary for reimbursement of all nursing activities except ADL-assistance After a referral by a doctor, a first or second level nurse pays an assessment visit to decide whether it concerns a dependent, a very dependent or an independent patient, using a scale developed by Katz et al (1963) to determine the patient's degree of care dependency This assessment of dependency determines how the care will be financed Finally, in Germany and France the assessment is always done by a doctor, who also prescribes the nursing care

In summary, there is a tendency that in the countries where a prescription of a doctor is needed, home nurses are less autonomous in the assessment of the need for 
nursing care and the decision about the provided care compared with home nurses in countries where no medical referral is required

None of the countries reported formal warting lists for home nursing This implies that when patients are in need of nursing care at home, they will receive it within a few days after the assessment has been made However, in a number of countries, Austria, France, Greece, Ireland, Italy, Portugal and Spain, large differences exist between regions in the supply of home nursing Consequently, the accessibility of the services is not the same for people who need care In many parts of Greece, Italy and Spain, home nursing services are even not avallable This means that within the policy of substitution of home care for hospital care, patients have to stay in the hospital too long or have to rely solely on the informal care of their families

\section{The relation between home nursing and home help services}

The growth in the number of elderly induces a greater need for home nursing and home help services Consequently, in many countries policy makers recognuze the advantages not only of co-operation, but also merging the two services into one organization

There seems to be a tendency within Europe towards integrating home nursing and home help services Table 4 shows that in Denmark and Ireland both services are part of the same organization In Denmark the services are organized by the municipalities and in Ireland the two services are broadly under the community care programme of the health boards, although their relationship is not uniform in all regions In Austria, Finland, France, Germany, the Netherlands and Sweden both services are often integrated In Germany the two services are integrated in the Sozıalstationen and are provided from the same location, improving possibilities of contact between different professions The number of integrated Sozıalstationen is still increasing In the Netherlands, the umbrella organizations for community nursing and for home help services merged

Table 4 Level of integration of home nursing and home help services into the same organization in the 15 countries of the European Union

\begin{tabular}{|c|c|c|}
\hline $\begin{array}{l}\text { Part of the same } \\
\text { organization }\end{array}$ & $\begin{array}{l}\text { In many } \\
\text { orgenizations }\end{array}$ & $\begin{array}{l}\text { In some } \\
\text { organizations }\end{array}$ \\
\hline $\begin{array}{l}\text { Denmark } \\
\text { Irelend }\end{array}$ & $\begin{array}{l}\text { Austria } \\
\text { Finland } \\
\text { France } \\
\text { Germany } \\
\text { The Netherlands } \\
\text { Sweden }\end{array}$ & $\begin{array}{l}\text { Belgium } \\
\text { Greece } \\
\text { Italy } \\
\text { Luxembourg } \\
\text { Portugal } \\
\text { Spain } \\
\text { United Kungdom }\end{array}$ \\
\hline
\end{tabular}

in 1990 At this moment this integration is taking place at the regional level In 1994, about $50 \%$ of the home nursing organizations had already merged with organizations for home help services It is hoped that the integration will increase the efficiency in home care and will avold unnecessary overlap between home nursing and home help services As already mentioned, the Swedish Act on 'The Care of the Elderly Reform' in 1992 moved the responsibility for the care for the elderly, including home nursing, towards the municipalities (Berleen et al 1994) At the end of 1994, in about $50 \%$ of the counties, home nursing had already been delegated to the municipalities, this reform process is strll going on As a consequence of this reform, home nursing becomes a part of social services and will belong to the same organization as the home help services In some regions home nurses and home helps already work together in a team

Belgium, Greece and Luxembourg have some organizations for both types of services In addition, in Belgium multi-disciplinary co-operation initıatives are subsidized on the condition that general practitioners, community nurses, home helps, social workers as well as three other professions take part in them In the private sector of the United Kingdom there are organizations which provide both home nursing and home help services Furthermore, one of the major conditions for the new approach in home care in the public health system is an extended co-operation between home nursing and home help services, 1 e consultation between social services and health agencies is required Finally, in Portugal and Spain, developments are taking place towards more intensive co-operation between the two disciplines Integration of the two services has recently been established in a few places, sometumes as an experiment

\section{CONCLUSIONS}

All member states of the European Unıon are confronted with an increase in demand for home care This is a result of, firstly, socio-demographic pressures, such as ageing of the population, the fertility trend towards smaller family size, and an increased female participation in the labour market and, secondly, the policy of substutution of home care for hospital care in order to control the health care expenditure

There are, however, large differences between the member states in the level of development of home nursing services In countries such as Belgium, Denmark, Finland, Ireland, the Netherlands, Sweden and the United Kingdom, home nursing is rather well developed, although in Sweden regional differences still exist in the level of co-payment by the clients On the other hand, in countries such as Austria, Greece, Italy and Spain, home nursing is still in its infancy In addition, there are large differences among the countries regarding the level of 
co-ordinating home nursing and home help services In general, there is a trend toward more co-operation between the two services, in a move towards efficient supply of home care, but much remains to be done in this area A major problem in many countries is the separation between health and social services Whereas home nursing is financed from general taxation or social insurance, home help services are usually administrated and financed by local government or sometımes by voluntary organizations

\section{Large differences in care and finance}

In general there are also large differences between the countries in the way home nursing care is financed There seems to be a relation between the way of funding and the organizational structure In member states where the organizations receive a fixed budget based on the number of inhabitants or the demography of the catchment area, home nursing is mainly provided by one type of organization and is freely accessible for the patients In this situation there is little competition among the organizations because the catchment areas of the regional organizations do not overlap On the other hand, in countries like Belgium, France and Germany where organizations are reimbursed according to a fee-for-service principle and a referral from a doctor is required, home nursing is provided by different types of organizations and also by independent nurses It seems that fee-for-service reimbursement stımulates competition between providers and a market-oriented home care In addition, a fee-for-service method of funding has also the consequence that mainly technical nursing procedures and some basic care like bathing the patient are reimbursed, which leaves little room for nurses to perform preventive and psychosocial activities and to provide more integrated care (van der Zee et al 1994)

In the Netherlands and the United Kingdom the financing of home nursing is in a transition penod from budget funding to fee-for-services reimbursement On the basis of the experiences in other countries one can expect that the nurses in the Netherlands and the United Kingdom will be confronted with changes in the content of their job more time has to be devoted to (complicated) technical nursing procedures and less tume will be avalable for preventive activities and psychosocial problems of the patients and their informal carers

On the other hand, the countries resemble one another in the problems they face in home nursing A shortage of qualified home nurses was reported in Austria, Denmark, France, Greece, Ireland, Italy, Luxembourg and Portugal In some countries the experts reported that hospital nurses were better pard than home nurses and that equal payment would help An uncreasing number of part-tımers was also reported to be a reason for staff shortage, as well as the fact that nurses remain in the profession for only a short tume A second problem that was reported in most countries concerned the co-ordination of care According to the experts in nearly all countries problems exist in the co-operation between hospitals and home nursing These problems concern the preparations for discharge, tumecontinuity between hospital care and home care, and the lack of knowledge of hospital staff concerning the possibilities of aftercare at home In addition, in some countries (France, Germany, Greece and Spain) problems in the co-operation with General Practitioners were mentioned

In summary, it can be concluded that the unification of Europe with regard to the organization and financing of home nursing is still far away, not only because there are large differences between the member states, but also because of larger regional differences within some countries On the contrary, the problems encountered in home nursing seem to ignore the borders of the member states There is, however, an advantage to all this Nurses who decide to work abroad will soon feel at home although the organizational and financial settıng will be different, they will encounter very familiar problems

\section{Acknowledgements}

This study was commissioned from the NIVEL foundation by the European Association of Organizations for Home Care and Help at Home, Brussels The project was funded by the Dutch Foundation for Research and Development of Community Health Care (Stichting Onderzoek en Ontwikkeling Maatschappelıke Gezondheidszorg STOOM)

\section{References}

Abel-Smith B \& Mossialos E (1994) Cost containment and health care reform a study of the European Union Health Polıcy 28, 89-132

Berleen G, Rehnberg C \& Wennström G (1994) The reform of health care in Sweden Swedish Institute for Health Services Development, Stockholm

Hutten JBF \& Kerkstra A (1995) Home Care in Europe NIVEL, Utrocht

Jamieson A (1991) Home Care for Older People in Europe Oxford University Press, Oxford

Katz S, Ford A B , Moskowitz R W, Jackson B A \& Jaffe M W (1963) Studies of illness in the aged the index of ADL a standardized measure of biological and psychosocial function Journal of the American Medical Association 185, 914-919

Nijkamp P , Pacolet J , Spinnewyn H, Vollenng A, Wilderom C \& Winters S (1991) Servces for the Elderly in Europe A CrossNational Comparative Study HIV/VU, Leuven/Amsterdam

Organization for Economic Cooperation \& Development (1990) Ageing Populations the Social Pohcy Implications OECD, Pans Raffy-Pihan N (1994) L'hospitalisation à domicile Un tour d'honzon en Europe, aux Etats-Uns et au Canada Credes, Pans 
Statistical Yearbook of Norway (1990) Statistisk Sentralbyrü Statıstısk Sentralbyrá, Oslo-Kongsvingen

Verhel] RA \& Kerkstra A (1992) International Comparative Study of Community Nursing Avebury, Aldershot

Walker A (1991) Home Care in Europe Current Trends and Future Prospects European Association of Organizations for Home Care and Help at Home, Brussels de Witte L, Knops H, Pyfers L \& Röben P (1994) European Servces Delivery Systems in Rehabiltation Technology IRV, Hoensbroek.

van der Zee J, Kramer K, Derksen A , Kerkstra A \& Stevens F C J (1994) Community nursing in Belgium, Germany and the Netherlands Journal of Advanced Nursing 20, 791-801 
This document is a scanned copy of a printed document. No warranty is given about the accuracy of the copy. Users should refer to the original published version of the material. 